Recibido: 29-julio-2013

Aceptado: 09-agosto-2013

\title{
LA COMUNIDAD ANTAGÓNICA: WALTER BENJAMIN Y CARL SCHMITT EN SU APROXIMACIÓN AL ROMANTICISMO ALEMÁN
}

VÍCTOR GUERRERO APRÁEZ

Facultad de Ciencias Políticas y RR.II.

Pontificia Universidad Javeriana de Bogotá 
RESUMEN

La polémica relación intelectual entre autores tan dispares e igualmente influyentes para el pensamiento contemporáneo como Walter Benjamin y Carl Schmitt ha sido objeto de aproximaciones tanto filosóficas como políticas particularmente debatidas pese a las radicalmente diferentes trayectorias de ambos pensadores. Temas comunes como la teología política al igual que la teoría de la soberanía así como su respectivo mesianismo revolucionario y conservadurismo contrarrevolucionario han sido materia de análisis. Sin embargo, su compartido inicial encuentro con el llamado Movimiento Romántico alemán de comienzos de la antepasada centuria que se materializara en sendas obras seminales tituladas El concepto de crítica en el romanticismo alemán, de una parte, y de la otra, Romanticismo político, han permanecido huérfanas de una indagación apropiada. El propósito del presente artículo es el de contextualizar esta común aproximación y efectuar una valoración de su significado e implicaciones en sus respectivas obras y trayectorias vitales en el contexto de su época.

Palabras clave: romanticismo, Schlegel, Novalis, Jena, Weimar, revoluciones Francesa y Bolchevique, crítica, emancipación, conservadurismo, fragmento, recensión, proyecto.

\section{ABSTRACT}

The polemical-intellectual relationship between the work of Walter Benjamin and Carl Schmitt as paradigmatic german thinkers at the beginning of the past century has been an issue particulary contested by both philosophical and political approaches in spite of their radical different paths. Common themes like political theology and the theory of sovereignity, the revolutionary messianism and counterrevolutionary conservatism have been highly debated and passionated thematized. However, their initial encounter with the so called Romantic School in the early eighteenth century which was materialized in two seminal works The concept of critique in the German Romanticism in one side, and Political Romanticism at the other has scarcely received attention in the academic literature. The aim of this article is to contextualize these common approach and attempt to assess the significance and divergence of these common works within their intellectual production and existential trajectories in their historical epoch.

Keywords: romanticism, Schlegel, Novalis, Jena, Weimar, French revolution, Bolchevist revolution, critic, emancipation, conservatism, fragment, review, project. 
En media centuria de reflexión académica volcada con pasión y sin limitaciones fronterizas idiomáticas o geopolíticas sobre las densas y complejas obras de Walter Benjamín y Carl Schmitt, como paradigmáticos intelectuales que encarnaron con extrema consecuencialidad una perspectiva revolucionaria al tiempo que su diametralmente opuesta tendencia contra revolucionaria, las convergencias, puntos de contacto y entrecruces referenciales entre ambos han sido objeto de una extensa y asombrada dedicación (Menschke).

Con toda razón los respectivos eruditos en la obra de uno y otro descubrieron estupefactos la carta laudatoria que Benjamin enviara a Schmitt al inicio de la década de los años 20 en el contexto de una precaria institucionalidad democrática donde los antagonismos políticos de izquierda y derecha desgarraban los frágiles consensos de un régimen cuya subsistencia dependió de un respaldo ciudadano que siempre le fue esquivo, y cuya ausencia o fragilidad terminaría por revelarse como decisivo para el trágico desenlace de su destrucción. La célebre carta admirativa que Benjamin escribiera a Carl Schmitt estuvo a punto de perderse para siempre debido al celo dogmático de Theodor Adorno, ese ambiguo colega amigo pero también celoso centinela presto a condenar cualquier desviación de la ortodoxia marxista- que negó su existencia por considerar incompatible esa extraña aproximación entre el pensador mesiánico de la revolución y el apologeta del decisionismo autoritario (Taubes). De no haber mediado la intervención de Jacob Taubes, el rabino filósofo detentador de la cátedra de "Hermenéuticas" en la Universidad Libre de Berlín -admirador de Benjamín e interlocutor de Schmitt condenado por sus compatriotas-, probablemente la correspondencia benjaminiana se habría visto despojada de una de sus piezas más inquietantes y reveladoras.

Sin embargo, aquello que ha sido descuidado por parte de la crítica posterior, y a lo cual el presente escrito busca aproximarse desde la tensión entre ambos pensadores, es justamente la circunstancia de haberse orientado las dos primeras producciones intelectuales de los dos autores exactamente a la misma veta filosófica producida por el pensamiento alemán: el romanticismo finisecular del siglo XVIII surgido en Weimar y Jena. Ese poderoso movimiento intelectual que a modo de un cometa vertiginoso irrumpiera en el tempestuoso paisaje de su época para producir un estremecimiento cuyo sacudimiento contribuyera a forjar el pensamiento así como a rescatar la identidad de una nación hechizada entre la admiración y el repudio suscitado por la Revolución Francesa -tanto como políticamente liquidada por la invasión napoleónica-, en el que se habría de fraguar el idealismo absoluto filosófico desde las cenizas de la crisis del sistema imperial romano germánico.

El interrogante central consiste en dar cuenta del significado que para un filósofo y un jurista, ambos con inmensas apuestas intelectuales -quizá el viejo nombre de eso que hoy pomposa y vanamente llamamos 'interdisciplinariedad'- y lúcidamente conscientes del sentido político que se jugaba en las disputas de su tiempo, tenía el acudir, en un movimiento de pensamiento estrictamente común, o el dirigirse a las formulaciones teóricas de una corriente que hasta entonces había permanecido en el cerrado coto de 
especialistas literarios y académicos universitarios. ¿Cuál era el sentido de abordar justamente el período romántico alemán y una pléyade de idénticos autores cuyos planteamientos podrían considerarse exógenos a los urgentes debates políticos propios de la república de Weimar y cuáles fueron las estrategias conceptuales para el examen de dichos contenidos desde sus respectivas ópticas teóricas? Al mismo tiempo, esa interrogación no puede ser cabalmente respondida si no se toma en consideración el papel que los contenidos conceptuales ganados o producidos en dicho abordaje teórico desempeñarían en sus respectivos trazados intelectuales y obras posteriores de cada uno.

La pertinencia e inquietud de esta interrogación se agudiza aún más por la circunstancia temporal en la que se enmarcan ambos trabajos teóricos tempranos, El concepto de crítica en el romanticismo alemán que Benjamin publicara en 1919 y Romanticismo político que Schmitt diera a imprenta un año después, pero cuya respectiva redacción se remonta en ambos casos al menos dos años atrás: de una parte, su carácter seminal e iniciático los configura como verdaderos reservorios de la mayoría de temas y autores que posteriormente serán la materia prima de sus desenvolvimientos teóricos constituyendo una primera formulación in nuce sobre el problema de la secularización, el estado así como las corrientes políticas surgidas bajo el impulso de la Revolución Francesa (Schmitt) al igual que las nociones cruciales de crítica, fragmento, autonomía estética y mesianismo político (Benjamin); de la otra, su estricta simultaneidad temporal dado que ambas fueron concebidas, escritas y publicadas al final de la Primera Guerra Mundial en medio de los acontecimientos que alumbraron la República de Weimar, pero no menos de cara a la reciente Revolución Bolchevique cuya posible extensión y continuación en Alemania se experimentara con ansiedad como un posible escenario de la respectiva coyuntura histórica en la que ambos autores se encontraban sumergidos.

\section{El trasfondo del romanticismo en la obra inicial de Benjamín y Schmitt: revoluciones Francesa y Bolchevique}

Planteado en otros términos, ambos pensadores, desde las extremas orillas de su sensibilidad y orientaciones políticas claramente antitéticas, se dieron a la tarea de enfrentar filosóficamente el colapso del orden imperial alemán que fundado bajo la égida de Guillermo I y bajo la conducción inicial de Bismarck hubo de conducir al desastre de la Primera Guerra, y de manera especial, afrontar en términos teóricos el inherente vacío de poder a tal desfondamiento al igual que la pasajera pero no menos crucial coyuntura de la posible implantación de una república proletaria en sustitución del viejo orden que fugazmente se encarnara en los consejos revolucionarios espartaquistas. La experiencia revolucionaria lejos de ser un referente lejano fue una evidencia real y casi íntima, dado que el ímpetu logró que los consejos obreros instalados en territorio alemán durante algunos días detentaran el poder en ciudades como Múnich. Justamente en la capital bávara Benjamín cursó un año de sus estudios filosóficos en la universidad muniquesa. Esta coyuntura histórica que momentáneamente puso de presente la inusitada inminencia del advenimiento de una república roja en el corazón de un país militarmente vencido e interiormente desgarrado entre los sectores 
conservadores militaristas nostálgicos de la monarquía y los movimientos obreros activamente comprometidos en el establecimiento de una dictadura proletaria, constituyó sin duda un paisaje convulsionado que marcó de manera indeleble a toda una generación de estudiantes alemanes. Esta misma generación educada bajo el Imperio y que concluía sus estudios bajo un régimen democrático habría de ser la misma que, ya en su madurez productiva, enfrentaría o se adheriría al régimen nacionalsocialista. Los efectos o lo que podría llamarse las implicaciones cognitivas de la Revolución Bolchevique -cuyas posibilidades de extensión al resto del continente europeo llegaron a adquirir una inminencia casi fatal no se clausurarían sino hasta finales de 1920 con la derrota del ejército rojo ante las puertas de Varsovia- ostentan un interesante paralelo con el tipo de conmoción intelectual que algo más de una centuria atrás la Revolución Francesa había suscitado en la joven generación de artistas, profesores universitarios y consejeros de los pequeños reinos alemanes, quienes debieron enfrentar teóricamente en medio de una profunda agitación existencial las consecuencias inducidas por este cambio de época que trastocaba por completo las coordenadas hasta entonces familiares del mundo clásico europeo (Ayrault). Si bien la variedad de posturas adoptadas por sus figuras mayores y en ciernes no puede ser tratada en el presente texto, la profundidad y variedad de las huellas dejadas, desde la fidelidad a ultranza de un Kant que no dejaría de encontrar en el fenómeno revolucionario una contundente prueba histórica del progreso y el arribo de la humanidad a su mayoría de edad, hasta el alejamiento y la censura de los excesos jacobinos en figuras como Goethe, Schiller,
Fichte y Hegel, puede cotejarse con los efectos que a su turno la revolución soviética dejaría en figuras como Bloch, Adorno, Cohen, Kantorowickz, y una docena de intelectuales, entre ellos, Benjamin y Schmitt.

En el contexto inmediato de la Revolución Francesa que se viera acompañada del desmantelamiento completo de las estructuras políticas de Alemania cuando Napoleón creara la Confederación del Rin, la joven generación de cabezas pensantes había respondido con la formulación de un nuevo horizonte en las dos coordenadas cruciales de la filosofía y la estética. De una parte, el ambicioso programa de la absolutización del pensamiento y la poetización del mundo esbozado por la exaltación y entusiasmo de los hermanos Schlegel y Novalis que supuso un giro conceptual de enormes consecuencias en la estética y la política plasmado en los manifiestos, apuestas teóricas y lecciones contenidos en las páginas de una publicación que no sobrepasó los dos años de existencia pero cuyas repercusiones habrían de modificar para siempre el paisaje intelectual de su época: el Atheneaum. De la otra, el inmenso desarrollo del Idealismo Absoluto como proyecto filosófico capaz de superar las contradicciones e insuficiencias del kantismo que se materializaría en Fichte, Schelling y Hegel.

La íntima y extraña relación intelectual que ambos autores tejieron en vida y que se tejería póstumamente sobre sus respetivas trayectorias, desde las orillas políticas más opuestas que quepa imaginar, tuvieron en las citas que de La Dictadura hiciera Benjamín en su malograda tesis doctoral El origen del drama barroco alemán, una de sus expresiones más acabadas cuya 
relevancia enfatizaría la carta mencionada. Pero esta convergencia que testimonia una inicial comunidad de intereses por temas comunes y textos igualmente atrayentes encuentra su primigenia manifestación o su primigenio lugar en la común vuelta de sus miradas teóricas al movimiento romántico alemán en los albores mismos del siglo XIX. Salvo esta convergencia precoz todo lo restante al igual que su compartida pasión por lo teológico político ha sido suficientemente examinado. No así, sin embargo, su compartido interés por el movimiento Romántico, que presenta tantos aspectos sorprendentes y reveladores de las distancias iniciales que el tiempo tan breve para el uno -Benjamin se suicida a los 48 años- $y$ tan extenso para el otro -Schmitt casi llega a la centuria cronológica- no harían sino ahondar a partir de esa convergencia inicial hasta ahora poco explorada.

Son bien conocidas las circunstancias en medio de las cuales el estudiante de filosofía acogería como tema de su disertación los escritos románticos tempranos. Inicialmente interesado en la filosofía kantiana la atención de Benjamín pronto se desplazó ante lo que llamara la "desvergüenza académica universitaria" típica de una producción despreocupada de la entidad propia del lenguaje que no vacilaba -sino más bien exigía- degradar a este para convertirlo en medio de un determinado conocimiento, arruinando así su poética. Si bien el opus kantiano le ofrecía un sólido terreno filosófico este carecía de un efectivo proyecto de una posible filosofía de la historia que sirviera en el presente de una Alemania devastada por la guerra y desgarrada entre las pulsiones revolucionarias y las impetuosas nostalgias monárquicas. Era clara la cualidad del lenguaje kantiano, no en vano, como lo recordara Benjamin en su correspondencia con Scholem, su potencia había sido capaz de afectar tanto a un Kleist estremecido hasta la crisis personal por sus conclusiones relativistas (Correspondence Carta 58 p. 288). Pero para el graduando Benjamin el filón histórico de una obra como Consideraciones sobre la Historia desde un punto de vista cosmopolita carecía de la intensidad suficiente para servir a sus propósitos donde filosofía, estética y política formaban una unidad necesaria e inescindible. En lo que sería una constante posterior de su obra, Benjamín encontraba un cruce de caminos particularmente apropiado donde el proyecto filosófico del idealismo alemán se conjuntaba con las especulaciones sobre arte, y donde todo ello se articulaba a un impulso mesiánico, incluso teológico-político, propio de un movimiento que se había planteado la construcción de una nueva sociedad europea. Fue el hálito mesiánico del romanticismo temprano el elemento decisivo en la asunción de sus postulados estéticos como materia de la disertación académica (Benjamín). Pero el costo a pagar era la renuncia a un tratamiento explícito de ese elemento, que quedaría apenas aludido en sus páginas iniciales en provecho de su concentración en la noción de crítica.

\section{El significado filosófico y político del romanticismo alemán}

Los inicios del romanticismo alemán puede ubicarse alrededor de 1795 cuando una pléyade de jóvenes literatos y ensayistas se reunieron alrededor de la figura central de Friedrich Schlegel y Novalis en torno a la publicación llamada Ätheneum, desde donde formularon una nueva concepción de las artes, asignaron inéditas tareas a la 
historia, conceptualizaron bajo premisas hasta entonces desconocidas el sentido de la propia Europa y concibieron la cultura desde un lenguaje forjado en el yunque de sus peculiares sensibilidades. La ruptura entrañada por sus postulados, el apasionamiento de sus posturas, la genialidad de sus autores y la entrañable comunidad que en menos de una década construyeron a partir de sus propias trayectorias vitales, bastaron para determinar un período histórico, es decir, fundar una época por breve que fuese, un referente sensible y una nueva palabra que matizó el denso paisaje de los imaginarios y sensorios europeos en los comienzos del siglo XIX añadiéndose al complejo léxico necesario que diera cuenta de las transformaciones que sacudían al continente.

Una corriente renovadora de ensayos, poesías, novelas, escritos divulgativos, correspondencias, traducciones, artículos periodísticos e incursiones en la vida pública, por parte de autores como Novalis, Federico Schlegel y su hermano Augusto Guillermo, Müller, Brentano, Jean Paul, Tieck, Wieland, Hoffman, Kleist, Bettina von Arnim y el propio Jakob Arnim, a los cuales se añadirían las misivas y cartas dirigidas por y a sus amadas, como Sophia von Kuhn, la adolescente que inspiró el amor apasionado de Novalis, todas ellas en su conjunto constituyeron la obra colectiva a partir de la cual se originó y dio nombre al movimiento. En alguna medida se reconocieron como herederos $y$ continuadores del movimiento conocido como Sturm und Drang -Tempestad e Ímpetu- que en las dos décadas anteriores había introducido una nueva sensibilidad cuando no un nuevo pathos poético, y alrededor suyo gravitaron con fuerza propia autores como Schiller y Holderlin, cuya respectiva obra se encuentra próxima a la romántica, pero es claramente diferenciable.

Los románticos desarrollaron a la par de una nueva concepción del arte las premisas teóricas indispensables para arribar a ella y se reclamaron de aquellos pensadores para cuyos propósitos resultaban útiles las herramientas conceptuales construidas en sus propias obras. Ello fue acompañado de una práctica literaria y estética en el sentido más amplio que prácticamente alcanzó todos los géneros y de una necesaria relación polémica con el más influyente y dotado de los autores de su época, el olímpico Goethe que desde las alturas de su magisterio indiscutido dictaba los cánones del arte, frente al cual discreparon con energía pero sin llegar a su liquidación.

Observado desde el ángulo de la filosofía alemana, los autores románticos suponen una especie de cesura entre la obra de Kant y Fichte de la cual se nutren con cautela y de manera variada, y aquello que bajo la égida de autores como Hegel y Schelling habría de configurar el Idealismo Absoluto, cuyas premisas en ocasiones avizoraron y parcialmente compartieron. A la obra romántica más cercana de los primeros es aquello que Benjamin llamará en su ensayo el Protoromanticismo, y a aquella cercana a estos últimos, es la que Schmitt por su parte denominará el Subromanticismo. En uno y otro autores, hondamente enraizados en la Alemania de Weimar, la temprana y apasionada remisión a esta fuente de reflexión surgida a su vez en el período de mayor crisis de los reinos alemanes de entonces, habría de significar una confrontación crucial dentro de sus respectivas trayectorias vitales e intelectuales, cuyas correspondientes 
elaboraciones conceptuales les procurarían nociones y perspectivas determinantes para su producción posterior. Esta inicial Auseinandersetzung con el pensamiento romántico determinará una intensa influencia en sus obras de madurez, en su postura ideológica y en su propia vida, revelándose con ello como un encuentro lleno de consecuencias, y especialmente como una opción teórica que habrá de caracterizar de manera singularmente perdurable todo el decurso posterior de ambos autores.

El significado profundo en el plano filosófico e histórico que el Romanticismo ostentó en el paisaje intelectual y político europeo ha sido objeto de una nueva contextualización en la obra de diversos autores, quienes desde una estricta contemporaneidad en las décadas de los años ochenta y noventa se enfrentaron a las implicaciones filosóficas y literarias del movimiento romántico. De acuerdo con Hans Blumenberg, dentro del proceso de la construcción de la Modernidad como espacio de ocupación y reformulación de los problemas fundamentales que la Antigüedad había establecido, el movimiento romántico de Jena emerge como el lugar donde la gran metáfora del libro de la naturaleza obtiene una de sus expresiones más acabadas en el nuevo libro de la Historia, ${ }^{1}$ situando con mayor precisión la singularidad del movimiento romántico en su teoría del conocimiento respecto de las concepciones respecto de las que tomaba distancia. Así mismo, su esencial contribución al advenimiento del campo conceptual de lo que en adelante suyo y gracias a sus postulados, habría de llamarse lo "literario" puede calibrarse con mayor nitidez partiendo de los trabajos

${ }^{1}$ Hans Blumenberg, La legibilidad del mundo, Buenos Aires, Paidós, 2003. inaugurales de Blanchot encuentran su continuidad como divergencia en Philip Lacoue Labarthe \& Jean Luc Nancy, ${ }^{2}$ dentro de aquello que puede denominarse como una revaloración radical de ciertos contenidos románticos. Esta renovación contemporánea del interés por lo romántico obtuvo en Ranciére una continuación crítica en la que se destacó de nuevo la centralidad de la teorización romántica sobre la forma literaria. Los aspectos develados en esta suerte de resurgimiento de la actualidad romántica permiten arrojar nuevas luces sobre el común sentido profundo que hubo de llevar a nuestros dos autores a cruzar su trayectoria intelectual y vital abrevando en los manantiales delirantes e inquietantes del romanticismo temprano y tardío, dotándose con ello cada uno de sus respectivas herramientas y marcando así mismo sus derroteros posteriores.

Dentro de su extensa obra -todavía en curso de publicación póstuma-, Blumenberg se ocupa de manera específica del romanticismo y su significación epistémica dentro del proceso de emergencia, consolidación y fractura de la Ilustración, en su obra La Legibilidad del Mundo. De acuerdo con su planteamiento, las intuiciones formuladas por Novalis a partir de 1796 en asocio de su intensa correspondencia intelectual con Friedrich Schlegel justo en el período del cambio de siglo y la publicación de los primeros números del Atheneaum, ambos autores propugnaron como máxima tentativa del movimiento en el que se encontraban inmersos, la imperiosa tarea de "romantizar el mundo". La dimensión y hondura de esta propuesta no era otra

\footnotetext{
${ }^{2}$ Phillipe Lacoue-Labarthe y Jean Luc Nancy, L'absolu Litteraire - Théorie de la Littérature du Romantisme Allemand, Seuil, 1978.
} 
cosa en el fondo sino la descomunal respuesta intelectual y estética que estos jóvenes talentosos y audaces consideraban debía proporcionarse al estado de cosas producido por las secuelas de la Revolución Francesa y el trastorno desencadenado por el naciente orden napoleónico que había puesto patas arriba todo el sacrosanto sistema dinástico hasta entonces vigente en Europa.

Herederos del movimiento literario del Sturm und Drang que apenas una década atrás había liquidado la literatura burguesa alemana con postulados de renovación y tábula rasa, Novalis y Schlegel, se situaban tanto en sus estelas renovadoras como en las ondas de la filosofía de Fichte quien inspirado en Kant pero tomando distancia del maestro, había intentado efectuar una refundación de la filosofía a partir de la necesidad de superar el considerado inadmisible relativismo de una 'cosa en sí' inalcanzable para el conocimiento mediante la trascendentalización de un yo que en su certeza absoluta de sí mismo resultaba capaz de abarcar el mundo exterior en su totalidad. Novalis efectuó una apasionada lectura de Fichte y se sirvió de su yo trascendental para reformular creativamente un yo personal quien desde su precoz apasionamiento juvenil se autoimpuso la tarea de escribir una nueva Biblia. Esto significaba entrar de lleno en el corazón mismo de uno de los campos metafóricos claves en la historia del pensamiento proveniente de la antigüedad, identificado por Blumenberg, como el problema metafóricamente planteado de la legibilidad de los dos libros, el de la Naturaleza y el de la Revelación -en cuya respectiva prevalencia o sumisión se jugaría el destino de la época- y sus consecuentes relaciones de correspondencia y oposición en cuyo decurso puede captarse un aspecto genealógico de la construcción de la filosofía occidental.

Si el libro de la Naturaleza fue el topos de la filosofía griega y helenística formado este por las letras del universo, el cielo, las estrellas y los cuerpos animados e inanimados de la tierra, cuya legibilidad exigía el conocimiento -al menos de la geometría tal como lo exigiera Platón en el dintel de su Academia-, por oposición al mismo y en radical confrontación suya, el Libro de la Revelación construido por los profetas, la patrística y el tomismo en un dilatado proceso de delimitación textual y apuntalamiento doctrinario, era el originario texto emanado de la sabiduría de la divinidad, compuesto por las frases provenientes de su propio intelecto ilimitado, cuya propia legibilidad precisaba de la fe, o al menos de una dosis suficiente de la misma. Cada uno de ellos como construcción metaforológica propia constituye un campo delimitado y consistente consigo mismo en cuyo interior determinados procedimientos de saber se autohabilitan para ofrecer una comprensión del mundo así como su correspondiente moral. Entre la variedad de posibilidades para su superación tras dos milenios de coexistencia, intuir una nueva posibilidad constituía ciertamente un gesto de arrojo individual y colectivo que se apoyó ciertamente en una profunda ruptura epocal.

La pretensión de Novalis a sus 17 años fallecería siete años más tarde- no fue otra que la consistente en asignar a sus corresponsales y a él mismo la creación o escritura de un libro que en estricta correspondencia con el bíblico incluyera la física, la química, la economía política, la filosofía, la matemática y la estética en el 
marco de una perspectiva histórica. Para tal empresa Novalis se auto concebía como un nuevo Mahoma o un Lutero de última hora embargado de un auténtico entusiasmo (Schwärmerei) que propugnaba una nueva sociedad continental, cuya propuesta política sería materia de un texto tan apasionado como discutible: Cristianismo o Europa. Esta tarea iba en consonancia y se encontraba posibilitada por la posesión de la capacidad de fantasía -que generosamente Novalis atribuía a Schlegel- la cual era calificada como el más apropiado "órgano para la captación de la divinidad" y cuya magnitud solo resultaba posible de acometer por esta nueva generación de profetas Schlegel sería un nuevo San Pablo en la exaltada escritura de Novalis-. Esta Biblia así concebida y proyectada, o mejor, soñada, con su novedad y atrevimiento insólitos tenía una funcionalidad epocal precisa: oponerse término a término a la Enciclopedia de los ilustrados franceses que en la mitad del siglo que ahora tocaba a su fin había sido puesta a punto por las imprentas parisinas con la no menor finalidad de tornar irreversibles los avances y progresos de la llustración.

No dejaba de resultar paradójico que el gran proyecto de autoafirmación de la razón iniciado más de una centuria atrás por Descartes terminase coagulado en un texto de amplísimo alcance que como tal era su propio libro de la Naturaleza como Enciclopedia de la Humanidad. Esa pretensión sistemática y concluyente ya había sido objeto de crítica por pensadores como Herder, que puede ser calificado tanto de proto romántico como de anti ilustrado, para quien, el gesto intelectual de erigir al medio de los medios (el libro) como fin de todos los fines, no podía sino constituir un síntoma revelador de la crisis
- la fragilidad que socavaba desde su interior el proyecto de la llustración como época del advenimiento de la mayoría de edad humana -particularmente en su versión francesa-, en todo caso de todo aquello que los críticos filosóficos de Hamburgo (Hamann y Jacobi) encontraban no tan solo poco atrayente, sino incluso, inquietante $\mathrm{y}$ en último término, hasta peligroso. Mientras Hamann, El mago del Norte -como lo calificara Isaiah Berlin-, se había opuesto acerbamente a su compatriota Kant acusando sus categorías trascendentales como elementos conceptuales provenientes de la misma demonología (Golgotha und Sheblemini) su corresponsal Friedrich Jacobi por su parte, no había vacilado en su relación epistolar con Mosses Mendelsohn en acusar la reverenciada figura de Lessing -un verdadero emblema de la llustración misma con su racionalismo moderado y su búsqueda de la concordia- de un soterrado spinozismo que en las tensas relaciones filosóficas del tardío siglo XVIII equivalía nada menos que a una comprometedora imputación de ateísmo.

La escritura de esta nueva Biblia que anuncia e inaugura una época distinta, cuenta con sus propios profetas y apunta a un futuro inédito, en cuya redacción habrán de participar todos y cuyos límites en la práctica dejan de existir, extinguiéndose con ello las arbitrarias divisiones hasta ahora erigidas entre los géneros y los saberes, todo lo que va a obtener su formulación más acabada en el surgimiento de un tercer Libro, el Libro de la Historia. El romanticismo contribuyó a la introducción de la historia como horizonte del saber y como condición del mismo en cuyo desarrollo se superarían las antinomias engendradas por los dos libros hasta entonces instituidos como tales. La 
apelación a la historia se encadena estrechamente con la puesta en cuestión y relieve de uno de los flancos que la Ilustración acusaba como problemático. Qué había sido de la razón y a qué obedecía su extravío o su letargo durante el extenso período temporal anterior a su despertar; cómo legitimar entonces o a partir de allí su consecuente autofundación a partir de la insuficiencia de $y$ en contraposición a los extravíos y confusiones de la tradición de la cual necesitaba deslindarse radicalmente como condición de su propia existencia, o del vacío sin o con exiguos antecedentes, cuya afirmación radical conllevaba una no menos problemática creatio ex nihilo. En otras palabras, la historicidad de la razón, era aquello que a la fundación cartesiana en el desarrollo subsecuente a su despliegue había empezado, de manera creciente, a emerger como un flanco particularmente lábil a objeciones y refutaciones. Por ello resulta inmensamente decisivo en la interpretación de Blumenberg que el descubrimiento de la Edad Media por los intereses epistémicos y literarios del Romanticismo se hubiese dado justamente -en el marco de este apasionado y exaltado intercambio epistolar entre Novalis y Schlegel- en 1798, el mismo año justamente cuando Napoleón decreta la instauración de una república en los Estados Vaticanos y hace prisionero al Papa como gesto inaugural político de la imparable y definitiva republicanización de Europa en su conjunto. Esta coincidencia o convergencia enlaza en un punto de entrecruce el plano del desarrollo político y el plano del desarrollo intelectual conteniendo en su cifra el posterior desenlace de la llustración, la Revolución y el Romanticismo. Y quizá sintetiza mejor que cualquier otra interpretación el cúmulo de contradicciones, ambivalencias y conversiones de las que fueron presas los miembros de los círculos románticos respecto al gran evento revolucionario. Lo que en el plano político apareció en su momento como la expresión más acabada de la entronización definitiva de las consecuencias de la Revolución merced a la cual extendía sus presupuestos políticos al reducto histórico por antonomasia del derecho divino de los reyes y la justificación dinástica de la monarquía segando con ello no solo su bastión sino su fuente ideológica y doctrinal, correspondía en el plano intelectual a la emergencia de la construcción teórica más incisiva y duradera que haría del socavamiento de los presupuestos ilustrados su propia y exitosa razón de ser: la romantización política e histórica.

Con su exaltada mirada hacia el pasado medieval el Romanticismo otorgaba carta de ciudadanía al mundo de mitos, leyendas, sagas, fantasías y ensoñaciones que de una parte, desnudaban el subsuelo reprimido por el racionalismo ilustrado, y por la otra, reinstalaban un antes epocal idealizado y seductor que la Revolución había pretendido abolir de un plumazo, o mejor, de un guillotinazo, es decir, de un golpe absoluto para el nuevo comienzo. Con su gesto embriagado y fantasioso redescubriendo o mistificando un Medioevo que oscilaría en adelante entre el ensueño y lo feérico, el romanticismo había descubierto la gran veta por la que toda una poderosa e influyente corriente de pensamiento europeo, desde Burke hasta Maurras, desde el finisecularismo del siglo XVIII hasta las postrimerías del XIX, habría de cavar inconteniblemente a fin de desplegar sus afiladuras críticas contra los fundamentos de la revolución y el espíritu del republicanismo. Esta conjunción de las 
coordenadas políticas y filosóficas -a las que su época daría continuidad bajo la acuñación napoleónica según la cual él era el espíritu absoluto entrando en Jena luego de la batalla de Austerlitz y que el propio Goethe comprendería como una aparición de acentos prometeicos o divinos si bien después lo tomaría en sus sesgos demoníacos- pone presente de manera fundamental la conexión crucial y problemática entre el romanticismo y la revolución. Contribuye a entender en especial la ambivalente relación sostenida por la filosofía alemana con la Revolución Francesa, cuya inicial exaltación, ejemplarizada por Kant y su entusiasmo ante la misma que se expresaría mejor que en cualquier otro texto en su opúsculo de 1795 titulado La paz perpetua, daría lugar progresivamente a un creciente desencanto respecto de las consecuencias por ella generadas, desde la ejecución de la pareja real hasta, especialmente, el desencadenamiento de las jornadas de terror impuestas por el Comité de salud pública para la salvación de la patria, y finalmente a un rechazo cada vez más categórico que terminaría por convertirse en un colectivo listo a volverle la espalda; lo que distingue y epitomiza de manera particular la experiencia vivida por la joven generación de los románticos acaballados entre los dos siglos como herederos de dicha tradición, fue contraponer al evento histórico que cambió las coordenadas políticas y culturales europeas un mundo paralelo o alternativo nimbado en las brumas de lo mítico configurando probablemente la más influyente y perdurable de las reacciones erigidas en su contra. El intento crucial de liquidar el pasado en provecho de un porvenir por construir, incierto pero valioso, se encontraba de súbito con la instauración de una seductora época pretérita que fungía como idealidad desconocida merecedora, más que de recuperación, de una reactualización beligerante y estratégicamente conducida. Esta peculiar resonancia, que sin abandonar su inicial afinidad con la revolución retomaba su ímpetu transformador y radical replanteamiento del conjunto del pensamiento incorporaba al mismo tiempo atisbos y nociones que posteriormente cobrarían especial relevancia en la lucha contra la revolución, constituye el suelo común que emparenta en sus diversas pero análogas coordenadas temporales y epocales a los románticos de Jena alrededor del cambio de siglo, de un lado, y del otro, a los dos intelectuales rivales, filósofo el uno y jurista el otro, que en los albores de la República de Weimar ante la lograda Revolución de Octubre en 1917 y la frustrada revolución espartaquista de 1918 , tomaron sus respectivas posiciones intelectuales y las construyeron apelando, eligiendo y de cara a sus predecesores situados algo más de una centuria atrás.

Si el Romanticismo se observa desde la aproximación contemporánea francesa de Blanchot, Lacoue-Labarthe \& Nancy y Ranciere, obtenemos una visión que enfatiza desde una perspectiva diferente el fondo de la transmutación romántica: la emergencia inicial e iniciática de la literatura como universo autónomo y autofundante que reemplazaría para siempre el mundo clásico de las Bellas Artes introducido bajo un imperativo absoluto sobre cuyo gesto y horizonte la estética no ha dejado de transitar desde entonces. Se trata del aspecto literario del movimiento romántico y el desplazamiento tectónico que sus esfuerzos terminaron por posibilitar en un universo que hasta entonces había sido el de la estética aristotélica clásica. Los románticos 
alemanes crearon en sus ensayos $y$ fragmentos publicados durante dos años y seis números en el Atheneaum el espacio teórico del absoluto literario como un ámbito propio para el despliegue de una nueva sensibilidad en el que se aunaban una forma específica, la novela o el roman, y una inédita construcción conceptual todavía signada por tanteos, aproximaciones e intuiciones, constituida por el fragmento, la recensión, la ironía y el Witz. Desde esta doble arboladura que destaca la imbricación política al igual que su especificidad teórica resulta posible dar cuenta con mayor precisión de las necesidades y vínculos que enlazaron los respectivos abordamientos de Schmitt y Benjamin.

Pese a todos los equívocos que rodearon y todavía dominan la valoración actual de los románticos, a cuya ambigüedad e incluso ambivalencia su misma obra contribuyó notoriamente, no pueden olvidarse las decisivas tomas de partido en favor de la Revolución Francesa que tanto Novalis como Friedrich Schlegel hicieron con palmaria nitidez en el contexto de apreciaciones encontradas. Este deslindamiento resulta de especial importancia a la hora de contrastar el sentido y alcance que la influencia de su obra tuvo tanto en Benjamin como en Schmitt puesto que mientras este último habrá de privilegiar las posturas partidarias de la restauración monárquica que los románticos adoptaron especialmente en su fase tardía cuando sus principales miembros se convirtieron en funcionarios del imperio austrohúngaro, aquél tomará la producción romántica inicial durante la cual la cercanía de los románticos a la revolución fue muy resuelta. Durante este período Novalis pudo sostener que "me parece que ahora sesiono en el Comité
Universal de Salud Pública". ${ }^{3}$ En estricta consonancia el propio August Wilhem Schlegel, quien posteriormente renegaría de tal postura como un verdadero contrarrevolucionario impenitente pudo incluso todavía sostener a finales de 1799: "Figuraos que toda la literatura alemana se halla en una situación revolucionaria y que todos nosotros, mi hermano, Tieck, Schelling y algunos otros somos el partido de la Montaña". 4 Este alineamiento de inequívoco tinte político en favor del movimiento revolucionario era además concebido como una postura común que se justificaba por y se compartía con las figuras referenciales de su época tal como Friedrich Schlegel lo sostuviera:

La Revolución Francesa, la Doctrina de la Ciencia de Fichte y el Wilhem Meister de Goethe son las más grandes tendencias de la época. Aquél que se ensombrezca por esta correlación y a quien ninguna revolución le parezca importante porque no es brillante $y$ material, es quien todavía no se ha elevado hasta el amplio y elevado punto de vista de la historia de la humanidad.

Esta toma de partido inicial habría de tener como contrapartida una década después una adscripción al bando opuesto de la restauración monárquica y una serie de conversiones al catolicismo por parte de Friedrich Schlegel y Clemens Brentano.

\section{La aproximación de Benjamin al romanticismo: afinidades y programas de acción}

\footnotetext{
3 R. Ayrault La génese du romantisme allemand, Aubier, 1961, T.I. p.168.
}

${ }^{4}$ R. Ayrault, Ibíd., p.169. 
La reflexión romántica sobre el arte toma su punto de partida de la fundamentación filosófica de Fichte. El arte como ejercicio de la actividad pensante se aloja en el medio de la reflexión y la obra artística proporciona la determinación para el ejercicio de la crítica que se encuentra a medio camino, o flota, entre el representante y lo representado, pudiendo dar cuenta de manera absoluta del producto estético y el medio donde se encuentra. Esta actividad reflexiva que es también de enjuiciamiento constituye propiamente la crítica, que al compartir con dicho objeto sus características reflexivas se sitúa como un complemento o un método de consumación de la obra. Los románticos adoptaron, según Benjamin, con la fuerza de un credo metafísico, la autonomía de la crítica y su elevado estatuto cognoscitivo situado en un perfecto plano de igualdad con la obra, aboliendo con ello un dualismo que se revelaría arbitrario, contribuyendo a su propia inmanencia pero también a la elevada exigencia de su tarea. La continuidad entre ambas implica la igualdad de medios -la crítica poetizada para la poesía- orientada a su absolutización, que es equivalente a su romantización. De allí deriva la distinción radical entre comentario y crítica que Schlegel teorizó de modo preciso y el situar a la recensión como un complemento de la obra estética. La autonomía de la obra de arte entraña a su turno la autonomía de su crítica en cuanto esta habrá de ubicarse en el ámbito de la reflexión sobre la reflexión de la forma pura que aquella implica. Con todas sus connotaciones esotéricas del empleo de la palabra "crítica" esta se independiza de cualquier atributo de juzgamiento abandonando con ello cualquier aspecto semejante a un tribunal erigido para la exhumación de su objeto al modo kantiano. En la medida en que el pensamiento derivado del yo absoluto de Fichte se entrega a una totalidad reflexionante en medio de la cual se encuentra la obra de arte, su crítica habrá de ser necesariamente su continuación. Y en tanto su misión esencial sea la búsqueda de esa forma absoluta, no hay contradicción en que llegue a ser también su propia consumación. La absolutización crítica encuentra su fundamento y refleja a la vez la exigencia de Fichte de un yo afirmativo y constituyente capaz de pensamiento que se abarca a sí mismo al igual que el mundo.

Benjamin identifica con la mayor claridad posible, yendo más allá de las contradicciones y oscuridades que afectaron los escritos tempranos y tardíos de Friedrich Schlegel, el centro de la tentativa romántica, cual fuera, no la aspiración sistemática al absoluto, sino la absolutización del sistema en el ámbito de la reflexión, y en particular del tipo de reflexión inherente a la obra de arte. Como su objetivo no es dar cuenta de las exigencias establecidas en el sistema mismo del pensamiento referido al conocimiento, ni a la ética, la religión o la historia, el campo delimitado por Benjamin es el de la obra de arte, para cuya delimitación se procede a deslindarlo del conocimiento de la naturaleza a fin de situarlo en el de la obra. Los románticos habrían trasladado sus observaciones de la naturaleza al ámbito del arte manteniendo sus postulados esenciales de un autoconocimiento para el cual en estricto sentido, no se dispondría de una tajante separación entre el objeto y el sujeto; tal como lo formularan, la afirmación de un objeto como tal enfrentado al sujeto implicaba de suyo la imposibilidad de una 
relación que pudiera aspirar a ser conocimiento.

Partiendo de la evidencia de la reflexión sobre sí y su posibilidad de remontarse sobre sí misma de nuevo con la inclusión de lo adquirido en la segunda a través de una ascensionalidad infinita -la potenciación del yo tanto como la extracción de raíces en su limitación- la obra de arte concebida como una suerte de naturaleza primigenia debía situarse necesariamente dentro de las coordenadas de la reflexión y sus lícitas aspiraciones de infinitud. En consecuencia la crítica de arte redefine o encuentra por vez primera su genuina posición epistémica y metodológica en función del objeto singular al cual se dirige que comparte con la naturaleza sus atributos de existencia. Ello implica la necesidad del autoconocimiento y el autojuzgamiento que en el ejercicio de su delimitación sea capaz de acoger en su interior la infinitud propia en los límites definidos -solo la limitación mediante la forma edifica el arte y es su condición esencial- habrá de permitir el despliegue de la crítica. El término de crítica se halla en una constelación mística de palabras cuya acuñación fue necesaria a los románticos para despejar las nociones de su época como seña de su audacia tanto como de sus insuficiencias. Junto a términos como idealismo mágico, ironía, proyecto, poesía universal progresiva, fragmento y Witz, la denominación de 'crítica' se hunde en el uso fundamental que de ella había hecho Kant pero se dota igualmente de aspiraciones nuevas que los románticos no pudieron sistematizar por completo. Al igual que en el filósofo de Königsberg la crítica se enfrentó a dos enemigos: el dogmatismo y el escepticismo. Este último, al que Schlegel había llamado "una insurrección lógica como estado provisorio, la anarquía en cuanto sistema, y como método un gobierno insurgente" (p. 44, Athenäum, p. 97) era la consecuencia de la reverencia al genio tributada por el Sturm und Drang y entrañaba de suyo un relativismo total al servicio de las ocurrencias de la genialidad, mientras el dogmatismo provenía de las reglas del buen gusto y de los cánones artificialmente elaborados a partir de las obras clásicas de la Antigüedad con base en los cuales se juzgaban las obras de su época conformes o indignas de satisfacerlos. Abandonando toda vocación enjuiciadora como consecuencia de las demandas rigurosas de su aproximación metódica -y con ellos la tendencia tribunalicia kantiana- el Romanticismo erigió la absoluta autonomía del arte a la par de la exigencia de su autoconocimiento como parte de esa conexión con el absoluto que constituía la sustancia del pensamiento. Así las cosas, la función de la crítica fue la de complementar, consumar, sistematizar y disolver en el absoluto la propia obra de arte. Los medios para hacerlo se dotaron en consecuencia de un sentido nuevo, en ruptura frontal con su época y plenamente modernos, pero especialmente, profundamente afines al talante intelectual del propio Benjamin. La recensión, por ejemplo, dejó de ser concebida como un comentario o caracterización para ser "el resultado y la exposición de un ejercicio de experimentación filológico y de recherche literaria" (p. 66, Athenäum, p .403), y como un complemento del libro.

De semejante manera, el fragmento, que había sido y sería la forma expositiva privilegiada por los románticos se autocomprendía como un medio para poner en relación la obra con el absoluto del cual hacía parte como corte suyo 
posibilitado por la forma; su propia capacidad fantasmagórica de conexión entre los términos conceptuales más distantes y disparatados -ese' romantizar' sobre el que Schmitt vuelca su mordacidad descalificatoria y al que calificará despectivamente de ocasionalismo- era una herramienta apropiada para recobrar la infinitud a la que la obra de arte hacía suya en su propia finitud. Los tres nuevos y revolucionarios principios que los románticos habían erigido como los mástiles del navío que despejaba el absoluto literario fueron, tal como los sintetiza Benjamin (p. 78) la mediatez del enjuiciamiento, la imposibilidad de una escala de valores positiva y el de la incriticabilidad de lo malo.

La obra de arte que engendra la posibilidad misma de crítica o lo que Benjamin llama su "criticabilidad" (p. 79) es lo que representa su valoración positiva, mientras que la obra que carece de esta condición no estaría en el terreno del arte. La particularidad es que la crítica misma carece de una escala de valores, con lo cual los románticos permanecían fieles a su idea de una imaginación sin hechos que pudiera surgir de su propia auto fundamentación o auto advenimiento, y en último término, a la propia auto posición del yo. Mediante la incriticabilidad de lo malo pusieron a punto la técnica de aniquilación de lo nulo mediante el medio indirecto del silencio. La absolutización del método romántico aplicado con el auxilio de la terminología mística, la recensión y el fragmento, tuvo como consecuencia el allanar el camino a la absolutización del arte, y en concreto, de la obra literaria. En su anticipación de lo moderno -o su autolegitimación como la llamaría Blumenberg- introdujeron también una diferencia no menos notable y fue, como lo señala Benjamin con especial énfasis (p. 68), la plena asunción de la completa positividad de la obra, en tanto la crítica moderna se aferraría a su irreductible negatividad. Lo aporético de la empresa crítica del Romanticismo por encontrar un absoluto y el punto esencial de articulación con el propio método benjaminiano consistió en haberse empeñado en ello a sabiendas de la carencia de un método acabado extraído de una teoría o doctrina más o menos elaborada, para lo cual carecieron del tiempo y la serenidad necesarias de cara a una época que asistía a cataclismos políticos continuos. Sin embargo, lo intentaron pese a todo, sobre la base del fragmento, es decir, de lo inacabado y lo inacabable, de una intuición y una reflexión que capaz de sistematizar se fijara sin embargo y de antemano un horizonte tan vasto y pluriforme que cualquier vida humana resultara insuficiente para llevarlo plenamente a cabo.

El laboratorio elegido para su puesta en práctica fue el Wilhem Meister de Goethe a quien Schlegel dedicara una de sus recensiones más importantes, que merece a su turno el elogio de Benjamín por haber designado lo contenido en la novela goethiana como super- maestro (Übermeister). Esta distinción habría de ser asumida con toda consecuencialidad por Benjamin, quien no solamente profundizó tal diferencia haciéndola la base de su propio proyecto -vital e intelectual- de crítico literario, sino que determinaría de modo semejante la escogencia de Las afinidades electivas, la otra gran novela de Goethe como la materia de uno de sus ensayos críticos más importantes, redactado a continuación de su trabajo sobre la crítica romántica de arte. 
Desde la perspectiva del impulso que movilizaba las energías románticas constituyó un factor relevante la crítica postura de un Herder hacia las limitaciones del kantismo cuyas provocaciones habrían de convertirse medio siglo después en el acicate de la tentativa romántica, y en particular de Novalis, quien como parte de los preparativos para la magna empresa refundacional y no exenta de toques mesiánicos con la que habría de iniciar su propia Enciclopedia, compuesta de fragmentos y no de artículos o apartados finalizados y totalizadores, había respondido a las exigencias de la irreductibilidad formal de la vida. En estos apuntes tempranos que compone siendo aún un adolescente, Novalis introduce con plena conciencia el empleo sistemático del fragmento como unidad o núcleo de una totalización del saber siempre en proceso y nunca acabada. Su deliberada utilización se corresponde aún más profundamente con la propia ubicación del proyecto romántico desgarrado entre la perspectiva de una unidad originaria y un desarrollo infinito orientado hacia un porvenir que se prepara y respecto del cual no se cierran, de manera que el fragmento se convierte en una asíntota de la totalidad, un medio escritural perfectamente consecuente consigo mismo, tanto en el plano intelectual como político. El fragmento es tanto una astilla del paraíso como del futuro posible al cual se encamina la época y del que se recuerda su existencia seminal -toda la honda reflexión acerca del origen de las lenguas y las acuñaciones conceptuales primigenias que obseden a los predecesores del romanticismo tanto como al propio Benjamin a lo largo de su obra-. Pero el fragmento es también el vehículo apropiado para una intuición que flota sobre los saberes y el mundo en cuya articulación se conjuga el macrocosmos con el microcosmos, los puntos más alejados y aparentemente inconexos de los distintos saberes, las honduras de las cavernas -Novalis había hecho estudios de minería y había sido adepto del siderismo y el vulcanismo- y las lejanías infinitas del cosmos, en una mezcla arremolinada de intersecciones causales y analógicas que conjugan todas las escalas y planos de la realidad y del espíritu.

Los románticos literalmente flotan (schweben un término que utilizaron con inmoderada frecuencia según NancyLacoue Labarthe) en el entrecruce de todas las determinaciones y los saberes. ${ }^{5}$ La reivindicación, para no decir su invención deliberada, del fragmento como modalidad privilegiada para la exposición de la postura cognoscitiva del Romanticismo es compartida plenamente por Friedrich Schlegel, y ampliamente destacada por Benjamin. Esta inclinación va acompañada por una exaltación de las palabras y de las mismas letras en su poder de convocación y en el contenido ideal que en ellas reside. Esto había sido visto con toda claridad por su hermano, Wilhem, quien en su correspondencia había destacado que lo más notable en su producción eran "las cartas por encima de los tratados, los fragmentos respecto de las cartas, y las palabras en relación con los fragmentos". Enraizados a su vez en el pensamiento kantiano y dependientes de la valoración extremada que le asignaron a su crítica, la función del fragmento se nutre de una profunda vocación crítica, al punto que las modalidades de su empleo hacen equivalentes a una y otra, de manera que resulta una redundancia el llamar críticos a los fragmentos como quiera que estos conllevan o portan en sus entrañas tal

\footnotetext{
5 Jean Luc Nancy - Philippe Lacoue Labarthe, L'absolu Littéraire, p. 420.
} 
condición. Ello termina por conducir a un misticismo de las palabras donde sus implicaciones desbordan su mera condición lingüística, situándose cerca del Hölderlin que había vislumbrado el poder letal de los grafemas griegos como elocuciones capaces de infligir la muerte.

De igual manera la recensión en tanto modalidad plenamente autónoma y de continuación a la par de la obra literaria misma como el fragmento en su condición de herramienta expresiva y recurso del pensamiento habrían de convertirse en dispositivos medulares del conjunto de la obra posterior de Benjamin. Más aún, su estilo y obra resultan indisociables de la profundización que ambas formas literarias experimentaron dentro del ámbito mayor de la propia lengua alemana. Los dos centenares de recensiones que escribiera antes y después del ascenso del nazismo bajo su propia rúbrica o con los pseudónimos que las necesidades de supervivencia vital y económica le impusieron, en las cuales se ocupó con lucidez y agudeza del movimiento literario, filosófico e intelectual de su época, no fueron un mero expediente ocasional sino el laboratorio donde se probaron intuiciones, se detectaron tendencias y se iluminaron surcos nuevos de reflexión. Pero especialmente, la praxis intensiva de la recensión fue para Benjamin la herramienta que permitió continuar y expandir los hallazgos y vertientes realizados en sus obras mayores, en una dinámica de actualización, contrastación y puesta en cuestión. A su manera, la recensión servía como una vía para la infinitización de la crítica en el continuo natural de la obra de arte y de la misma crítica de esta. La extensión y diversidad de los temas tratados a través de la recensión fueron una continua puesta en movimiento de una transdisciplinariedad gozosa donde podía desplegarse el erudito, el filósofo, el crítico de arte, el sociólogo, el historiador y el literato que habitaron de manera tumultuosa su condición intelectual. Al mismo tiempo fue el laboratorio conceptual donde se pulieron las metáforas que habrían de nutrir sus ensayos, el campo de la justa donde se medían fuerzas con los adversarios -las deslumbrantes recensiones dedicadas a Kommerell, George, Benda y Jünger donde el ascenso del nazismo se develaba en sus apologías de la guerra o en sus llamados místicos a un guía espiritual- o se fortalecían afinidades electivas -su apreciación de la obra dramática de Hoffmasntahl Der Turm y su exaltación del Berlin Alexandserplatz de Döblin-, o se continuaba su propio trabajo con el Romanticismo en las recensiones de Béguin.

Esas diminutas joyas pulidas en la lucidez y el rigor pertenecen al conjunto de su obra en toda la plenitud de su forma, no como productos menores sino como prolongaciones o inicios de sus textos considerados mayores. Para quien había visto cerradas las puertas de la universidad alemana de entreguerras a causa de la miopía de sus entronizados guardianes incapaces de comprender la audacia y el carácter anticipatorio del Origen del Drama Barroco Alemán que lo despojaba de cursos regulares y diligentes estudiantes encargados de tomar apuntes que permitirían la conversión de lecciones en libros acabados, la recensión fue el mecanismo de urgencia para unir la frenética e insaciable lectura -cuando su lista personal de libros leídos llegó al millar Benjamin lo hizo saber alborozado a su corresponsal- con el espacio de la escritura en un continuo sin interrupción ni cesura 
de género. En un movimiento semejante, cuando Benjamin se embarca en el proyecto de fundar una revista que habría de llevar el título de Angelus Novus -en alusión al célebre grabado de Klee que alegoriza su concepción de la historia-, su reclamo consiste en afirmar que fundar una revista sin la pretensión de cambiar su época, simplemente carecía de sentido, puede apreciarse su implícita alusión al Átheneaum.

El entroncamiento de la reflexión de Benjamin con los postulados del Romanticismo no se agotaría sin embargo en la continua utilización de sus herramientas teóricas, como el fragmento y la recensión, sino que se extendería en su ocupación de la producción crítica posterior relacionada con el mismo. Al menos en tres reseñas la confrontación teórica habría de prolongarse en un continuo proceso de refinamiento conceptual y valoración del fenómeno romántico en conjunto. En 1928 se ocupó de analizar una tesis doctoral editada en Tubinga bajo el título La filosofía del romanticismo alemán de EvaFiesel en la que señalaba el desbalance entre el cuidado universitario, de un lado, y la ausencia de una convicción propia sobre la esencia del romanticismo, del otro, esta última como condición necesaria para poder situarlo como una fase en el pensamiento general sobre el lenguaje de la humanidad (GS, III, pp. 96-97). Benjamin avanza un paso adicional al indicar que el Romanticismo había constituido un viento, una tempestad en ese ámbito del pensamiento inseparable de la "terminología mísitica" y de la "mística del concepto" propia de Friedrich Schlegel sin lo cual tan solo podría hacerse un cenotafio historicista ornado de guirnaldas compuestas por citas. Arremetió contra el uso de las fuentes originarias cuya combinatoria podría demostrar agudeza sin entrar en el esfera propia del lenguaje, máxime cuando se prescindía de la literatura posterior, conduciendo a una producción carente de educación. Exactamente una década más tarde la aparición de un ambicioso proyecto editorial previsto en tres tomos sobre la correspondencia sostenida en los círculos de los autores románticos bajo el título de Los años de crisis en el romanticismo temprano, editados por Josef Körrner, fue la ocasión de nuevas reflexiones (GS II, pp. 538-541). Benjamin pudo hacer una valoración más claramente política sobre el tema de su primera disertación destacando la minoría de edad padecida por la Alemania de la época que afectaba tanto el volterianismo de William August Schlegel como la tendencia ultramontana de su hermano Friedrich, dentro del contexto más amplio de un "campo de resonancia" que las aspiraciones emancipatorias de la llustración proyectaron sobre el movimiento. Es decir, pese a todas sus ambivalencias y contradicciones que el tiempo no haría más que acentuar, el carácter favorable a la revolución podía señalarse como una orientación estructural del movimiento romántico en la que en el marco del despliegue del nacionalsocialismo podía seguir siendo un aliado. Que el Romanticismo continuó siendo un referente constante en el pensamiento de Benjamin lo muestra con diáfana rotundez la recensión que un año antes de su muerte hiciera de la obra de quien había sido su amigo durante las aventuras de Marsella, El alma romántica y el Sueño de Albert Béguin (GS III, pp. 557560). Esta es notable por haberse escrito en medio de unas crecientes dificultades materiales que no solo determinaron su angustiosa falta de recursos sino que lo 
llevaron en sucesivas ocasiones a campos de internamiento dispuestos por las autoridades de Vichy. Allí se señala de nuevo el carácter incompleto de la interpretación del experto francés, quien, según Benjamin, no da cuenta del conjunto del movimiento romántico, en especial de su particular condición de haberse consumado en su interior una forma de secularización de lo religioso al mismo tiempo que una retracción bajo la modalidad de las conversiones al catolicismo que varios de sus miembros protagonizarían (Schlegel, Brentano). En veloces y fulminantes frases el recensionista finaliza sosteniendo que los sueños más que caminos hacia la emancipación fueron las señales de alarma levantadas para hacer notar los obstáculos que ellos mismos interponían en el camino hacia ella.

Pero quizá sea en el empleo del fragmento donde el opus de Benjamin encontraría la más afín a su talante teórico de las innovaciones de creación conceptual que los románticos habían contribuido de manera decisiva a ingresar en el repertorio de lo admisible. La extraña y profunda sintonía que vincula a Benjamin con Novalis encuentra aquí el elemento clave. A la común brevedad de sus vidas y su compartida condición de extranjeros respecto de su época y medio circundante se suma la maestría que uno y otro confirieron al fragmento como procedimiento filosófico y poético. La valoración del fragmento ha encontrado en los ya vueltos célebres textos de Blanchot una interpretación seductora en la que se destaca su carácter de inacabamiento, y desobramiento, en cuya textura la propia imposibilidad de la escritura y de la conclusión de la obra como exigencia de totalización se revelarían con la mayor intensidad, ya como una vocación irreductible de la propia obra, ya como una condición ineluctable de la misma modernidad. Sin embargo, como lo ha sostenido Ranciére quizá las cosas disten de ser tan patética, ${ }^{6}$ según como la exposición realizada por Blanchot las presenta. El fragmento no es una ruina ni el signo de una debilidad o flaqueza intelectuales pero tampoco la roca fatal en cuya cúspide de vértigo el autor ve socavada su propia obra por el buitre de la infinitud conceptual inabarcable. Los románticos conocieron de cerca la embriaguez del vértigo intelectual en esa continua excavación de las infinitudes del yo reflexivo que reflexiona sobre sí mismo en el océano de la reflexión, tal como Fichte lo presentara en el inicio de su aventura filosófica. Su opción por el fragmento como gesto de ruptura que sería llevada a su término extremo en $L a$ Enciclopedia de Novalis, confeccionada justamente por fragmentos (escorzos, frases sincopadas) encadenados de modo sucesivo, y en los Granos de Polen donde sus intuiciones relampagueantes se siguen unas de otras, fue deliberadamente un gesto hacia el futuro. Sembrar semillas de porvenir, gérmenes de posibilidad. A la estólida solidez del tratado Novalis y Benjamin opusieron la condición aporética del fragmento como lucidez aguda capaz de vincular conceptualmente los extremos más disímiles en un ejercicio riguroso de la intuición. Para decirlo en términos del propio Benjamin, frente al Angelus Novus que vuelve sus ojos desorbitados a las ruinas que la historia acumula frente a él, el fragmento opone una astilla utópica o un relumbre mesiánico que impiden su arrastre por el viento implacable de la historia. Ningún autor de lengua alemana

\footnotetext{
${ }^{6}$ Jacques Ranciére, La parole muette, essais sur les contradictions de la littératur, chapitre 3.
} 
llegaría a hacer del fragmento el uso intensivo que Benjamin le procurara. Desde el misterioso Fragmento teológico político cuya disputada fecha de redacción parece situarlo sin embargo en la misma época de la redacción del Concepto de crítica en el romanticismo alemán, con lo cual la tesis aquí sostenida acerca de la importancia decisiva de su encuentro con las apuestas teóricas de los románticos tempranos se sustenta y refuerza, hasta su obra de madurez que sería también la postrera, la fidelidad benjaminiana hacia su inicial encuentro con el romanticismo no sólo permaneció intacta sino que se profundizó hasta un punto crucial insuperable. El fragmento infinito $y$ el fragmento sintético se conjugan en esta saga de fidelidad y consecuencialidad. De un lado, El libro de los pasajes puede ser visto como el opus magnun de la cita y el fragmento, una obra singular e incomparable donde la génesis compleja y múltiple de la modernidad en el espacio de la infinitud urbana queda situada en una monumental colección de citas conectadas a modo de fragmentos enzarzados unos con otro cuya ordenación temática la proporciona un azaroso criterio alfabético sin comienzo ni final, y del otro, ese breve texto compuesto de fragmentos que Benjamin llevaba consigo como lo más preciado en el mítico intento fallido por cruzar la frontera franco española para ponerse a salvo de la máquina de muerte nazi en las cercanías de Port Bou: Tesis sobre la filosofía de la historia. El carácter abierto de ambos textos los ha convertido en el medio siglo posterior a su publicación en referentes insoslayables de toda reflexión sobre la modernidad y la utopía, pero lo que no ha sido suficientemente destacado es su honda impronta romántica cuya inspiración Benjamin encontrara desde muy temprano en su obra seminal. Y a la cual permanecería fiel hasta el final.

\section{Schmitt y el romanticismo: deslindamientos y repudios}

Schmitt redactó el texto inicial en 1920 y retornó a su contenido en un prólogo escrito casi un lustro después; a diferencia de la casi restante totalidad (salvo la Teología política) de su obra, ninguna de ellas fue objeto de una revaloración tan clara ni inmediata como la que se exhibe en este, y da cuenta de la importancia que una mirada retrospectiva tan pronta $y$ decididamente reivindicadora tenía para un autor cuyo ascendiente intelectual no había cesado de crecer en la densa discusión contemporánea de ese período. Las formulaciones del prólogo arrojan una luz insospechada sobre el trasfondo de lo que estaba en juego y será utilizado interpretándolo como un epílogo en relación con el método empleado, o mejor, como una suerte de confesión de su propia corrección y lo certero de su análisis. Más aún, de modo retrospectivo Schmitt validará su consideración sobre el oportunismo del romanticismo político alemán a la luz de la principal de sus herramientas teóricas construidas durante el intervalo que separa la obra de su prólogo, esto es, la distinción entre amigo y enemigo. En efecto, en 1918 Schmitt concluye el cuerpo principal de su diagnóstico sobre el fenómeno romántico en su vertiente política, para retornar sobre el mismo en 1925 en un prólogo que es más un epílogo triunfal, luego de haber finalizado nada menos que la fase inicial de su obra: La dictadura (1921), Teología política (1922), La situación del parlamentarismo actual (1923), y Catolicismo romano (1923). 
El problema fundamental que Schmitt enfrenta es la polivocidad y ambivalencia del fenómeno romántico en su vertiente política: "es romántico identificarse con todo, pero no permitir a nadie identificarse con el romanticismo; es romántico decir que el movimiento neoplatónico es romanticismo, que el ocasionalismo es romanticismo, que los movimientos místicos, pietistas, espiritualistas e irracionalistas de toda clase son romanticismo, pero no a la inversa" (p. 48 prólogo). Hay una constante confusión en la valoración de sus autores, una desconcertante policromía, una perpetua traslación en su caracterización doctrinaria y una continua equivocidad en las genealogías que se le otorgan. Esta aparente inasibilidad de sus contornos y ductilidad de su procedencia son aquello que el ensayo pretende superar mediante una doble apuesta metodológica que de suyo entraña un intento metafísico: "todo movimiento se fundamenta en una postura característica y determinada respecto del mundo, y en una representación no siempre consciente de una instancia última, de un centro absoluto" (p. 57 prólogo) lo que conlleva no limitarse a lo señalado por los propios textos de sus autores para en lugar suyo ubicarlos en una perspectiva más amplia capaz de dar cuenta de aquello que Schmitt denomina su postura (algo acentuado en el prólogo de 1925), y de otra parte, desentrañar el sistema de representación utilizado tras el velo de sus cambiantes afirmaciones, lo que podría llamarse su condición epistemológica. Los intérpretes franceses (Taine, Seilliére, Brunnetau) amalgaman una serie muy variada de autores y orientaciones que proviniendo de Rousseau con su individualismo y naturalismo se oponen frontalmente al clasicismo, y dotadas de irracionalidad y un gran caudal de energía provocan el fenómeno revolucionario de 1789.

Según Taine, el movimiento literario romántico es el disfraz revolucionario de la burguesía (p. 55 prólogo). Esto no resulta del todo claro y más bien contradicho por el desenvolvimiento posterior de sus principales exponentes adscritos a la Restauración (pp. 69, 71). De cara a ese acontecimiento los revolucionarios se llaman románticos y estos a su vez se declaran como enemigos de la Revolución, habiendo una gran multiplicidad de corrientes y estrategias de oposición. (p. 74). No es posible considerar como románticos a los pensadores conservadores de la contrarrevolución como Bonald, De Maistre o Donoso Cortés, quienes se encuentran alejados del paisaje literario creado por los románticos, así como no resulta apropiado llamar romántico a alguien como Burke pese a su acendrada oposición en contra de los hombres de 1789 y su aborrecimiento de una creación política alejada de la tradición; de igual manera no es coherente empadronar a Savigny como romántico pese a su alta valoración de la historia para explicar el derecho y la provocada renovación de sus estudios; tampoco a un Gorres pese a sus simpatías contrarrevolucionarias dado su posterior rechazo de la monarquía. Este ejercicio por distinguir las filiaciones y los exponentes en el seno de la variopinta y contradictoria multitud de los románticos tiene como propósito desentrañar en un ejercicio estratégico de acentos platónicos al verdadero adversario o aliado capaz de oponer una resistencia eficaz a la nueva mitología política revolucionaria. Esta viene a ser la común situación existencial que le une al movimiento romántico: mientras este fue la respuesta que la Alemania de 
entonces, postrada política y militarmente ante el genio napoleónico, pudo articular para enfrentarse a la Revolución y sus consecuencias, la tarea contemporánea y urgente para Schmitt se encuentra en la búsqueda de una construcción política que permita hacer lo propio frente a la Revolución Bolchevique y su posible expansión a la naciente Alemania de Weimar. Democracia que para sus enemigos no era sino la temporal concesión ante la derrota innegable del imperio Guillermino y su ineluctable superación restauradora o autoritaria que los círculos militaristas habrían de perseguir sin denuedo fracasando en 1918 pero saliéndose con las suyas en enero de 1933. Esos dos episodios históricos serían a posteriori nombrados por el novelista Alfred Döblin como "Un pueblo traicionado" y por el filósofo Odo Marquard, como la generación incapaz de decir no. ${ }^{7}$

Para que la exploración pueda cumplir su cometido esencial, esto es, desentrañar el sentido o identidad de fondo de esta multiformidad (que estilística y programáticamente se corresponde con la inclinación de Novalis por la figura de Proteo cuya mención es la más frecuentemente empleada en el conjunto de su obra entre todas sus referencias míticas) conduce a descifrar la posición metafísica del romanticismo político: se trata de un ocasionalismo subjetivo, esto es, un sistema de pensamiento que inspirado en los clásicos pensadores de

\footnotetext{
${ }^{7}$ La tetralogía de Döblin sobre el período del nacimiento de la República de Weimar constituye el testimonio literario más estremecedor de dicha época: 1918: Un pueblo traicionado; por su parte, la reflexión filosófica alemana casi como en ninguna ocasión se ocupó del Zeitgeist salvo en Odo Marquard Adiós a los principios (2005).
}

esta corriente, como Malebranche, supone un sistema de intervenciones divinas dejadas al arbitrio para cuando estas resulten necesarias; este sistema que habría tenido su propia grandeza, cae sin embargo, de la mano de los románticos en su subordinación al propio yo que ocupa el antiguo lugar eminente. A diferencia del movimiento filosófico inicial este desplazamiento es la condición de su fragilidad y su alejamiento ineluctable de cualquier posibilidad efectiva de intervención. Si el ocasionalismo clásico pudo haber constituido un "poderoso" sistema en el siglo XVII, se ve rebajado ahora a la cambiante subjetividad individual, degenerando en un oportunismo diletante e inocuo, cuando no rayano en lo ridículo, aspectos a los que Schmitt consagra prácticamente la totalidad del segundo capítulo, ejercitando una suerte de agotamiento probatorio propio de una demostración jurídica tribunalicia. La infinitud reflexiva y la consecuente capacidad inagotable de establecer relaciones es para Schmitt como riqueza vertiginosa de intuiciones y visiones entrelazándose a modo de explicaciones, constituye aquello que va a denominarse como el ocasionalismo, intentando ver en ello más una debilidad que una potencia del pensamiento, para derivar de ello en una suerte de consecuencia inevitable, el oportunismo político que habría de caracterizar a tantos miembros del movimiento.

Schmitt dedica un capítulo a lo que denomina la "situación exterior" bajo lo que entiende la posición asumida por los principales románticos -Friedrich Schlegel, Adam Müller, Gentz- dentro de la burocracia de la restauración promocionada por Metternich y apuntalada en la cancillería vienesa. Todos 
ellos fueron empleados como funcionarios suyos en condición de validos del mecenas Metternich a quienes este aseguró pensiones y reconocimiento no ahorrándoles el sometimiento a un trato despectivo, en ocasiones humillante, dentro de una atmósfera en la que los señores entendían la utilidad de las mentes de los antiguos románticos quitándole importancia a sus convicciones personales. Hay un cierto explayarse en hurgar los archivos y revistas en las que se encuentran los testimonios acerca del trato recibido en los pasillos palaciegos y en las antecámaras de los ministros: la desconfianza mostrada, el espíritu socarrón con la que eran acogidos, utilizados y soportados. Schmitt traza el retrato de estos arribistas resignados a asegurarse un puesto de funcionario o un reconocimiento económico auscultando informes y publicaciones de la época. Un Adam Muller empleado por Gentz (el primer traductor de Burke al alemán) para justificar el aplastamiento de las aspiraciones autonomistas del Tirol a manos de la máquina imperial austrohúngara, o un Schlegel tratando de mirar por encima del hombro de los funcionarios imperiales los expedientes de la alta política. Y ambos defendiendo, luego de sus espasmos revolucionarios, formas estamentales, monárquicas e incluso feudales de gobierno, como construcciones de la verdadera sociedad imbuidas ahora por el amor y la sensibilidad. Ello sería la huella de su fracaso histórico y de la falencia de su proyecto político que en estrecho maridaje con el "Doctor de las Revoluciones" como se conociera al poderoso canciller austriaco, no pudieron impedir el advenimiento de aquello que había sido concebido como el principal objetivo del régimen post napoleónico fundado en el ideal restaurador monárquico y la consiguiente eliminación, prospectiva y retrospectiva, de los levantamientos revolucionarios, es decir en términos epocales de su propia coyuntura histórica, el estallido de la revolución de 1848 y sus convulsivas repercusiones en los demás regímenes monárquicos europeos.

Este cuadro puntilloso y burlón no tiene finalidad distinta a la de corroborar el fracaso de la tentativa política del romanticismo que de suyo hundiría sus raíces en la postura y método propios empleados. Esa aureola de impotencia no exenta de ridiculez que nimba a los románticos políticos, tal como los describe Schmitt, es la evidencia de su fracaso sin atenuantes, cuyo exacto diagnóstico, a partir de los postulados propios del romanticismo, el texto schmittiano posibilitaría por vez primera. El diagnóstico preciso de ese fracaso es el seguro para evitar su repetición y encontrar la genuina estrategia que permitiese atender el desafío de su propia época. Justamente en el momento de las confusiones políticas y la proliferación de tendencias de la más diversa índole que campeaban en todos los espacios de discusión de todas las disciplinas filosóficas y científicas. Schmitt ejercita en su ensayo una práctica premonitoria de la identificación del correcto aliado y la identificación del falso modelo en medio de una circunstancia vital signada por la urgencia y radicalidad de las transformaciones; el hallazgo de este último es el objetivo del texto y la consecución de lo primero el resultado concluyente que expresaría con plena claridad en el prólogo posterior -que estrictamente es más un postfacio temporalmente-, y en especial, ideológicamente distante. $\mathrm{Si}$ las tres monstruosidades que habían dolorosamente signado el destino de 
Alemania, esto es, la Reforma, la Revolución y el Romanticismo, cuyo hijo ilegítimo fuera el Napoleón que había borrado la condición estatal prusiana, conformaban el hilo conductor al que debía oponerse una nueva construcción intelectual y política que Schmitt andaba buscando con toda la urgencia y angustia existencial que fuera capaz de resistir las fuerzas de la anarquía destructora de eso que en la república de Weimar era la amenaza de la revolución bolchevique cuyos ecos terribles golpeaban, durante la década de los años 20 en las puertas de las fronteras patrias y los oídos de los intelectuales, el encuentro con el romanticismo político fue una deliberada exploración en busca de armas conceptuales en el abrevadero romántico. Ciertamente Schmitt no las encontró allí, lo cual le tomaría una década adicional terminando por hallarlas en las tesis de los decisionistas contrarrevolucionarios como De Maistre y Donoso Cortés, y en los constructores de la soberanía como Bodino y Hobbes, pero empezaría a descubrirlos en la elaboración de este texto, y en un curioso giro del destino, acabaría reproduciendo el mismo periplo de los románticos tardíos extraviados en los pasillos del poder en Viena como él mismo en los pasillos de las oficinas berlinesas con los nuevos amos del poder en Alemania: los camisas pardas comandados por el carisma aniquilador, decisionista y consciente como ninguno de las delimitaciones entre amigos y enemigos.

La indagación del romanticismo político está continuamente signada por un desvelamiento de sus debilidades, inconsecuencias y finalmente, de su sentido fallido. El punto de partida romántico es el de una subjetividad a ultranza cuya exaltación como criterio último y definitivo de la validez de sus aproximaciones y asertos lo priva de toda posible coherencia demostrativa; son las impresiones causadas en una sensibilidad exaltada y que se promete a sí misma un horizonte inalcanzable lo que permite un salto continuo en los temas y las correspondientes valoraciones de los mismos, que pueden recibir un signo positivo y acto seguido una continuación enteramente contraria, como claramente negativa; esa postura subjetiva se erige en criterio de una nueva validez para sus puntos de vista intentando, en vano, ocupar el lugar de lo auténticamente genuino, de manera que el romanticismo descubriría una inédita y más certera aprehensión de las realidades que toca cualquiera que sean: lo político, lo filosófico, las artes, la reflexión, etc.; efectuando un acercamiento desusado entre el ocasionalismo filosófico de autores como Gueniceux y Malebranche, cuyos planteamientos y principales obras Schmitt rastrea con cierto detalle, al que caracteriza como un sistema de pensamiento donde los objetos sin excepción se conciben como verdaderas ocasiones para la actuación causal de dios de manera que toda realidad queda en el fondo subsumida en la voluntad divina de la que es el bastidor para su intervención productiva perdiendo con ello la autonomía de sus propias realidades, y la superación en un tercero mediador que no es otro que dios, el romanticismo político por conducto de Schlegel -quien en sus Vorlesungen über die Logik colocaba la obra de Malebranche por encima de la de Descartes p. 154) hace suyo esta forma de pensar con el fin de eludir las verdaderas causalidades y en su lugar aproximarse a los problemas no con el ánimo de resolverlos sino de disolver sus elementos integrantes, evitando con ello intervenir de 
manera efectiva; este ocasionalismo tal como lo describe Schmitt termina resultando muy cercano de un "oportunismo político" cuya evidencia se encuentra tanto en las contradictorias posturas asumidas por sus autores, como por su labilidad frente a la influencia de ciertas obras, y no menos por las opuestas calificaciones impartidas por sus contemporáneos: luego de entusiasmarse con la Revolución Francesa viendo en ella la posibilidad de una nueva época se vuelven en contra suya, para asumir un talante abiertamente conservador durante el período de la Restauración, y tras la revolución de 1830 que depuso la monarquía francesa con su entusiasta seguimiento en Bélgica, algunos de los autores románticos (Bettina von Arnim) retornarían a sus efusiones de antaño; la recepción de una obra tan influyente en el pensamiento político posterior como Las consideraciones sobre la Revolución Francesa, que fuera traducido al alemán por Gentz, uno de los suyos, bastó para inducir un cambio de actitud desde Novalis, quien la llamaría una obra revolucionaria contra la revolución; mientras los sectores nobiliarios verían a los románticos en su fase inicial como perturbadores del orden, la burguesía liberal posteriormente los calificaría como reaccionarios, para finalmente caer en un abierto filisteísmo y terminar sin huella alguna de tragedia al lado del Biedermeier -estilo del conformismo bien pensante conservador, aburguesado y romo-, en "un final quizá no deshonroso pero no trágico".

En la medida en que el romántico político no puede distinguir lo justo de lo injusto, debido a la preeminencia de una subjetividad cambiante y a un ocasionalismo donde termina siendo indiferente si se actúa o no, habrá de permanecer en el reino de la imaginación, la conversación, la sociabilidad, la correspondencia epistolar y los salones donde estas modalidades de pasividad encuentran su lugar privilegiado de manifestación. Incapaces de distinguir realidad de fantasía, fragmento de totalidad, instante y eternidad, inmersos como estaban en esa exaltación de la individualidad y la coexistencia en tensión de todos los opuestos (tal como se ridiculizan postulados contenidos en la Lehre der Gegensätze de Adam Müller: "cada cosa no es más que su opuesto, la naturaleza es al anti-arte, el arte es la antinaturaleza, la flor es lo opuesto de la antiflor, y por último, la misma oposición depende de la anti-oposición" (p. 152).

Provisto de tal caracterización, Schmitt puede entonces (Capítulo IV) distinguir con toda claridad al romántico político del político romántico, sirviéndose para ello de tres ejemplos, tan alejados unos de otros temporalmente como inesperados en su ausencia de conexión: el asesinato de Kotzebue en 1829, la figura de Don Quijote, y el personaje histórico de Juliano el Apóstata. Un hecho político de la historia en la formación del Estado alemán relacionado con las corrientes de su época, un personaje literario particularmente entrañable para los románticos tempranos al punto que Tieck hubo de traducir piezas literarias del siglo de oro español, entre las que se incluía a Cervantes, y una figura histórica del siglo III cuya significación fuera ampliamente debatida en los círculos académicos alemanes, especialmente en la obra de David Friedrich Strauss, cuyas atrevidas tesis le habían deparado enfrentamientos con las autoridades civiles de su época. El exaltado estudiante Sand viendo en Kotzebue un agente imperial zarista le propinó un pistoletazo creyendo con ello preservar los ímpetus 
revolucionarios que agitaban los principados alemanes; Don Quijote idealiza la realidad elevándola hasta lo sublime así se trata de la más prosaica, por lo que puede prendarse de posadera Dulcinea como si de una dama noble se tratara; Juliano el Apóstata intenta revertir el dogmatismo del monoteísmo cristiano erigido en religión oficial del Estado para volver al antiguo mundo de los dioses cívicos. Todas son tentativas finalmente improductivas en el plano de la realidad, carecen de la fuerza necesaria para transformarla permaneciendo como tentativas más o menos frustradas, pero son todas ellas en su peculiar manera intervenciones decididas, compromisos personales llevados hasta sus últimas consecuencias y plenos de consecuencialidad o coherencia, donde brilla el fulgor de la audacia o el atrevimiento.

El balance final de Schmitt no puede ser más condenatorio. Romanticismo político no es más que una sombra de las verdaderas y efectivas fuerzas reales que nunca sale de su propia esfera individual, "en el núcleo de su superioridad fantástica se esconde la renuncia a cualquier transformación activa del mundo real", se encuentra en incapacidad de fundar cualquier comunidad, tampoco cuenta con la potencia de construir un mito -este sólo puede surgir de la guerra-, la pasividad orgánica de la estructura ocasionalista asumida conduce al callejón sin salida de una productividad que pretende formarse sin ser activa, y en consecuencia, su imposibilidad de transformar su esencia espiritual en "conexiones teóricas o práctico-sustantivas". Con todo ello a sus espaldas, lo peor aún está por venir, el romanticismo político termina por ponerse al servicio de tendencias poco o nada románticas, no siendo más que una compañía servil de fuerzas ajenas y decisiones ajenas.

Schmitt se ocupó de manera crítica, sin ocultar asomos de sarcasmo, de las insuficiencias y contradicciones en las que se sumieron los románticos en sus posturas y producción intelectual tardías. Despedazó literalmente los escritos de Adam Müller señalando la inconsecuencia de sus decisiones políticas al servicio de la reacción encarnada en el conservadurismo de la monarquía austriaca, pero sin mencionar sus escritos sobre teología política que sin duda lo pusieron en contacto con un ámbito de reflexión que luego sería decisivo en su propia trayectoria intelectual. Sin embargo, no resulta descartable que de la prolífica obra de quien en su juventud fuera uno de los pocos y más cercanos amigos de Kleist, Schmitt haya iniciado o reforzado su interés por la teología política, dado el opúsculo que este autor romántico publicara justamente con ese título. No tuvo más que mordacidad para el viejo Friedrich Schlegel convertido en un burócrata cortesano cuyas juveniles aspiraciones de infinitud se habían trocado en sus rastreros cuando no patéticos apetitos burocráticos. Sin embargo, la lectura schmittiana del romanticismo habría de ser decisiva para la construcción de su propio sistema. Schmitt creyó identificar las debilidades e inconsecuencias de la respuesta romántica a los desafíos de su época como una falencia cuya envergadura liquidaba el conjunto de sus posturas. De hecho, cuando en su fundamental trabajo de Teología política casi cinco años más tarde, se ocupe en profundidad del problema de la excepción hará constar su distancia de cara a toda posible imputación de 
romanticismo en su aproximación a la misma como el problema fundamental del intérprete. Si en sus propias palabras, la excepción lo es todo mientras que la regla sólo se explica por la existencia de aquella, la referencia oculta a Kierkegaard no le releva de la precaución de advertir que en ningún caso su manera de abordarla sea o pueda atribuirse a un impulso romántico. En realidad con ello Schmitt no sólo marcaba una diferencia infranqueable con la metodología romántica sino que atribuía la novedad y radicalidad de su enfoque a la separación ganada respecto de todo lo que pudiera sonar a romántico.

Frente al amenazante fantasma revolucionario la única postura consecuente era la decisiva toma de partido en su contra, como lo señalaría no muy poco después en Catolicismo y forma política -donde resalta positivamente como modelo de consecuencialidad la toma de partido por parte de la Iglesia católica en contra del fenómeno revolucionario- con lo cual su derrotero antirrevolucionario se nutriría de un inagotable reservorio de creatividad conceptual en su denodado intento por oponer un contramito capaz de oponerse con probabilidades de éxito a la mitología insurreccional cuya potencia histórica efectiva de transformación había irrumpido victoriosa, y por segunda vez, en las inmediaciones geopolíticas de Alemania en el invierno de 1917 . La valoración estremecida y admirativa que recorre una y otra vez la obra de Schmitt en las dos décadas de los 20 y 30 respecto de la potencia del mito bolchevique da buena cuenta de cuál era el enemigo para cuyo discernimiento su contacto con los románicos lo había preparado. El conjunto de su conceptualización sobre el estado total al igual que su encantada valoración del proyecto de Mussolini a partir de 1922 que se erigía como el único capaz de oponerse al mesianismo del Octubre Rojo era la consecuencia inevitable de su toma de partido en favor de la Contrarrevolución como sola vía de oposición tanto teórica como material en contra de las monstruosidades detectadas.

Ciertamente para Schmitt era imposible oponerse a esa fractura telúrica con las herramientas de la monstruosidad romántica en cuyos entresijos contradictorios y confusos se había adentrado con el escalpelo de la correcta distinción entre el amigo y el enemigo. En su identificación como monstruos semejantes o funcionalmente equivalentes de los fenómenos históricos conformados por la Reforma, la Revolución Francesa y el Romanticismo -la R3-, en los cuales descubría una continuidad más imaginaria que real pero no menos efectiva en la identificación del adversario genuino, la lectura de Schmitt anticipa con particular clarividencia personal los enemigos contra quienes habría en delante de dirigir sus fuegos teóricos con incansable energía. E igualmente la escogencia de sus entrañables aliados con quienes se identificaría casi que de manera incondicional en su apuesta a favor de los decisionistas restauradores como De Maistre, Bonald y Donoso Cortés. Los tres pensadores contra revolucionarios podrían ser, a partir de esta obra, cuya composición le había permitido limpiarlos de cualquier veleidad romántica, los fieles compañeros de ruta en la osada tentativa de reconstrucción política de un proyecto restaurador para una Alemania sumida en la crisis. La exaltación de la restauración autoritaria pudo proclamarla en una obra inmediatamente posterior como Catolicismo y forma política donde su 
postura abiertamente opuesta a la revolución lo acercaba aún más a De Maistre. Su acendrado y militante catolicismo, que como oriundo del Sauerland no dejaba de ser una anomalía en el contexto de las reparticiones confesionales alemanas, practicado y ostentado a lo largo de su vida y en cuyas fuentes nutricias habría de encontrar la noción central del Kat'echon o mantenedor del orden ante el demonio, termina por consumarse en su vocación contrarrevolucionaria que lo condujo a su adhesión entusiasta e incondicional al Führer como encarnación de la novedosa potencia mítica que una Alemania fundida en su seno había finalmente reencontrado para oponer al orden internacional fundado en el sometimiento patrio con todas las garantías de su efectiva realización material. No deja de ser una de las mayores paradojas que los sarcasmos de Schmitt lanzados a la figura del burócrata Friedrich Schlegel finalmente pudieran volverse en su contra: el jurista de tan vastos horizontes filosóficos e históricos capaces de develar las taumaturgias del poder se halló errando por los pasadizos de los despachos oficiales del alto consejo gubernamental prusiano situado sobre la Willhemstrasse incluido en la nómina a cargo del mariscal Goering (Mehring, p. 378). Para un buscador tan empecinado como él la búsqueda de un principio de autoridad y de certeza no resulta extraño, pero sí más clara, su repelencia por el fragmento, las recensiones y los proyectos, géneros que nunca utilizaría a pesar de sus iniciales escarceos literarios, en los que se reflejaba la inconstancia e inconsecuencialiad de los románticos.

Finalmente, en el centro de su compartida Rückkehr hacia el movimiento romántico como urgido clivaje para intentar responder a los desafíos de una coyuntura histórica literalmente desangrada entre el abismo de la derrota militar alemana y el resplandor del utópico advenimiento de la revolución obrera, Benjamin y Schmitt adoptaron una idéntica orientación de sus miradas, pero en la concreción filosófica y política de dicha postura ambos construyeron líneas enteramente divergentes correspondiendo a su turno, a actitudes vitales en total oposición: la actualización crítica de las intuiciones revolucionarias que terminaría por convertir a Benjamin en el primer intelectual víctima del nazismo, y en sus antípodas, el rechazo visceral de toda concesión con la revolución, para identificarla como el principal enemigo que conduciría a Schmitt a convertirse en el jurista por breve tiempo coronado de ese mismo régimen. Mientras Benjamín se adentró en las entrañas del monstruo revolucionario para encontrar allí los destellos de la utopía mesiánica en nombre de los vencidos y las víctimas, Schmitt se puso del lado de los nuevos mantenedores del orden para salvar el mito de una excéntricamente mortal tradición germánica. Lo singular de ambos comunes y dispares movimientos consistió que el espacio teórico en donde se forjaron las dos trayectorias fuera el propio romanticismo alemán. 


\section{BIBLIOGRAFÍA}

AYRAULT, R. (1961). La génese du Romantisme Allemand.

BENJAMIN, Walter (1994). Correspondence Chicago University Press.

(1998). Gesammelte Schriften III Kritiken und Rezensionen Suhrkamp Verlag 1991.

(1998a). Gesammelte Schriften VII Vermischte Notizen Suhrkamp Verlag 1991

(2003). El concepto de crítica en el romanticismo alemán, Abada Editores.

BLANCHOT, Maurice (1995). La Conversación Infinita, Caracas, Monte Ávila.

BLUMENBERG, Hans (2005). La legitimidad de la modernidad, Editorial Pretextos.

(2001). La legibilidad del mundo, Editorial Paidós.

DÖBLIN, Alfred (2010). 1918: Un pueblo Traicionado, Edhasa.

LACOUE-LABARTHE, Philippe \& Nancy, Jean Luc (1987). L'absolu Littéraire - Théorie de la Littérature du Romantisme Allemand Editions du Seuil

MARQUARD, Odo (2005). Adiós a los principios, Ediciones Alfons El Magnanim.
MEHRIG, Reinhard (2003). Carl Schmitt.

NOVALIS (1980). La Enciclopedia. (2002) Semillas.

RANCIÉRE, Jacques (1998). La parole muette- Essai sur les contradictions de la Littérature, Ed. Hachette.

SCHMITT, Carl (2001). Romanticismo político, Universidad de Quilmes. 